\title{
RAE 45 ANOS: RECORTES DE SUA HISTÓRIA
}

\author{
Rafael Valente \\ Graduando em Jornalismo na Universidade Presbiteriana Mackenzie \\ E-mail: jornalismo.rafael@gmail.com
}

Maurício C. Serafim

Doutorando em Administração de Empresas na FGV-EAESP

E-mail: serafim@gvmail.br

Neste ano de 2006 a RAE-revista de administração de empresas comemora seus 45 anos. Lançada em maio de 1961 para atender o público acadêmico e inovar no campo da pesquisa em Administração de Empresas, desde seu início buscou promover o estudo e a reflexão crítica da área. Atualmente ela é a revista científica de Administração de maior abrangência de assinantes e a de maior presença nas bibliotecas das universidades.

A RAE foi criada pela Escola de Administração de Empresas de São Paulo da Fundação Getulio Vargas como um projeto ousado para introduzir um novo padrão de conhecimento científico em Administração no país, num mercado que se mostrava carente de publicações do gênero. Na época, a FGV também publicava as revistas Conjuntura Econômica, Revista Brasileira de Economia, Revista de Direito Público e Ciência Política, Arquivos Brasileiros de
Psicotécnica e Revista de Direito Administrativo.

Inicialmente a idéia foi a de criar uma revista que traduzisse e representasse de forma ampla o pensamento da Escola que estava se consolidando. O seu grande incentivador e realizador foi Raimar Richers, professor fundador da FGV-EAESP, que ocupou o cargo de diretor e redator-chefe durante os primeiros anos. O corpo redatorial era composto pelos professores Claude Machline, Isidoro Macedo, João Carlos Hoop (veja sua entrevista a seguir), Mauro Brandão Lopes e Pólia Lerner Hamburger. Provenientes de diversas áreas, esses professores constituíram uma equipe multidisciplinar. Participaram também Vergil D. Reed, como consultor técnico, e Yolanda Ferreira Balcão, como assistente técnica. A professora Yolanda Balcão teve participação ativa na história da RAE, inclusive na assunção da direção da re- vista, sucedendo ao professor Richers.

A RAE surgiu como uma revista quadrimestral. A sua redação e edição eram feitas em São Paulo, mas sua confecção e impressão eram feitas no Rio de Janeiro pela Editora da Fundação Getulio Vargas. Nesses anos iniciais, a principal dificuldade da revista foi a falta de pesquisadores e autores que escrevessem artigos científicos de administração, dado que essa área ainda era incipiente no Brasil. Devido a essa dificuldade, os artigos publicados eram predominantemente de trabalhos dos professores da EAESP. Uma outra característica importante é que na época não havia um sistema de peer review como atualmente. Os artigos eram selecionados de acordo com o tema e a área. A idéia era publicar artigos que cobrissem as várias áreas ou funções administrativas, o que se preserva até hoje. 
Como a revista vinha se tornando um veículo conceituado no mundo acadêmico, a periodicidade mudou para trimestral em 1963, e o número de artigos publicados aumentou, assim como o de contribuições recebidas, inclusive de autores externos à EAESP. Nesse período surgiu uma questão significativa: conhecer e entender o público da RAE. O problema fez com que Raimar Richers criasse um "Fórum de opiniões", com o intuito de aumentar o intercâmbio com os leitores. Foi uma boa experiência, que serviu também para orientar a edição da RAE, permanecendo durante muitos anos a melhor forma de conhecer o público da revista.

Quando completou dez anos de publicação, em 1971, a RAE passou pela primeira grande transformação da sua história. Foi um processo de reestruturação gráfica que resultou em modificações no tamanho da revista, na diagramação dos artigos e na estética das páginas. Nessa época se experimentaram novos formatos e estilos, que não tiveram seqüência por não terem correspondido às expectativas dos leitores. Devido ao crescente número de artigos submetidos à redação, houve uma tentativa de transformar a revista numa publicação bimestral, o que de fato ocorreu em 1974. Concomitantemente, o processo de avaliação e seleção dos artigos se tornou mais rigoroso. Em 1977 a revista voltou a ser trimestral.

Os anos 1980 trouxeram mudanças para a RAE, principalmente estruturais. A mais significativa foi a transferência da confecção e impressão da revista do Rio de Janeiro para São Paulo, em 1988, e o início do processo de informatização da Redação. Entre as outras mudanças, podem ser citadas: a inauguração de novas seções - como uma dedicada exclusivamente a colaborações internacionais -, um novo desenho gráfico, os artigos passaram a apresentar palavras-chave em português e inglês, o editorial passou a ser publicado em todas as edições e o sistema de avaliação blind review foi aperfeiçoado. Uma pessoa que teve um papel ativo nessas mudanças foi a professora Gisela Black Taschner (veja sua entrevista a seguir), que assumiu à RAE em 1986 como redatora-chefe e posteriormente como diretora, em 1990. Essa fase foi importante na história da RAE por, de certa forma, ter aberto espaço para as mudanças que foram realizadas posteriormente.

Logo que completou 30 anos de história - no início da década de 1990 -, a RAE passou por novas modificações estruturais, dessa vez sob a direção do professor Marilson Alves Gonçalves (veja sua entrevista a seguir), que assumiu em outubro de 1991 e permaneceu até novembro 1995. Dentre as mudanças, as mais importantes foram a segmentação de algumas seções para facilitar a consulta e a distribuição dos artigos na revista, a criação de novas seções, a adoção de um novo estilo, a criação da linha editorial, a inserção de ilustrações (algumas contaram com as contribuições do cartunista Ziraldo) e a volta da bimestralidade das edições após 14 anos. Além disso, o processo de distribuição e comercialização foi reestruturado, aumentando significativamente o número de assinantes.

Durante essa fase foi criada, em 1994, a RAE Light. A idéia era ter um suplemento da RAE com uma edição mais curta e sucinta, com prioridade aos alunos, professores e ex-alunos - que não eram necessariamente pesquisadores -, adotando-se linguagem mais apropriada a esse público. Em 1997 ela foi ane- xada à RAE, sendo extinta pouco tempo depois, em 2001.

Em 1995, o professor Roberto Venosa assumiu a direção da RAE, promovendo novas mudanças editoriais e com a atenção também voltada para uma estratégia de redução de custos. Com ele a revista voltou a ser trimestral, ganhou novamente um caráter estritamente acadêmico e iniciou-se o processo de padronização das edições. Foi o início também da aproximação da RAE com as publicações acadêmicas internacionais. Além disso, a revista voltou a representar o pensamento da EAESP, publicando trabalhos relacionados com as áreas de atuação da Escola, mas sempre explorando as diversas áreas de conhecimento da Administração.

Somando ao processo de aperfeiçoamento da RAE, o professor Thomaz Wood Jr. (veja sua entrevista a seguir), que assumiu a direção da revista em 2001, desenvolveu um projeto de padronização da RAE de acordo com as publicações acadêmicas internacionais, baseado principalmente nas revistas editadas pela Academy of Management. O projeto coincidiu com a regulamentação da Capes e a classificação das publicações acadêmicas.

Entre as mudanças promovidas, podem ser destacadas: a renovação do Conselho Editorial, a criação dos Editores Associados, renovação e ampla divulgação da linha editorial, ampliação do quadro de avaliadores e aperfeiçoamento do sistema de avaliação double blind review. Além disso, foram criadas novas seções, como os fóruns temáticos para debater temas importantes e apresentar novas tendências -, e a "RAE-clássicos", que tem o intuito de publicar artigos seminais para a pesquisa em Administração, a fim de torná-los acessíveis em português aos estudantes de pós-graduação e 
pesquisadores. Foi também o início da RAE-publicações, com a criação em 2002 da RAE-eletrônica e da GVexecutivo, e do portal RAE-publicações na Internet. Uma outra iniciativa importante foi a digitalização do acervo da RAE desde o primeiro número, de 1961, proporcionando a todos os pesquisadores, professores e estudantes o acesso aberto a grande parte do conhecimento científico em Administração no país.

A RAE-eletrônica foi criada pela necessidade de publicação de artigos aprovados pelo processo de avaliação, mas cujas publicações eram limitadas pelo espaço físico na revista impressa e pelo número crescente de artigos. Dessa forma, foram aproveitadas a capacidade e as vantagens proporcionadas pelo meio eletrônico, como a divulgação mais rápida e sem custos para quem o acessa, sempre mantendo a mesma qualidade de todo o processo de avaliação da RAE impressa. Essa qualidade foi reconhecida em 2005 pelo sistema Qualis/Capes, que pontuou a revista eletrônica como "Nacional A".

A GV-executivo - inicialmente RAE-executivo - foi criada como alternativa de leitura para o público diversificado da RAE. A proposta é atender os executivos, consultores, professores, alunos e ex-alunos com textos inovadores e relevantes para a prática administrativa.

Completando a RAE-publicações, foi lançada em 2004 uma edição especial intitulada RAE-Minas, baseada nas mesmas diretrizes da RAE e com o objetivo de refletir e divulgar a produção do estado de Minas Gerais. Sua segunda edição foi publicada em 2005, e todos os artigos das duas edições estão disponíveis gratuitamente no portal. A RAE-Minas é parte de um projeto mais amplo de exportar para outras regiões do país a expertise adquirida pela RAE acerca do processo de avaliação, edição e publicação de uma revista científica.

Em 2005 assumiu a direção da RAE o professor Carlos Osmar Bertero (veja seu artigo nesta edição), cargo que havia ocupado durante 1967 e 1968. Atualmente ele está consolidando os projetos da RAE-publicações e implementando em breve o projeto "Módulo de redação on-line" da RAE, que automatizará todo o processo de avaliação dos artigos.

Nestes 45 anos, a RAE-revista de administração de empresas buscou acompanhar e refletir o desenvolvimento da Administração em nosso país. Sendo a revista mais antiga em termos de publicação ininterrupta, a $R A E$, ao longo de sua história, teve um papel ativo e fundamental não apenas na publicação científica da área, mas também como um instrumento de aperfeiçoamento do campo científico e da prática administrativa no Brasil. Para conhecer um pouco mais essa história, a seguir são oferecidos trechos das entrevistas de alguns de seus protagonistas - João Carlos Hopp, Gisela Black Taschner, Marilson Alves Gonçalves e Thomaz Wood Jr. -, que contarão um pouco de suas experiências e sua época.

\section{ENTREVISTAS}

\section{JOÃO CARLOS HOPP}

RAE - Como surgiu a RAE e quem foi seu idealizador?

João Carlos Hopp - Se pudermos pensar numa pessoa que deu im- pulso à revista, ela seria o Raimar Richers. O Raimar sempre gostou de escrever. Ele era um professor da área de Marketing e inicialmente foi quem deu incentivo à área de Pesquisa. Foram feitas várias pesquisas na época e ele pretendia mostrar na revista o resultado delas. Agora, como a nossa Escola tinha uma formação iniciada, incentivada e acompanhada por professores da Michigan State University - e lá escrever artigos era muito importante -, também se imbuiu no espírito dos professores brasileiros a idéia de ter uma revista que representasse o pensamento da Escola como um todo. E se há uma pessoa que deu impulso, sempre apoiou a revista e incentivou os colegas foi o professor Raimar Richers, professor fundador da escola, da primeira turma.

RAE - Como funcionava a Redação nos primeiros anos da revista e qual era o objetivo inicial?

$\mathrm{JCH}$ - Note as pessoas que compunham a equipe: por exemplo, o Claude Machline era professor da área de Produção, o Isidoro Macedo era professor da área de Administração Geral, o Mauro Brandão Lopes era professor da área de Direito, a Pólia Lerner Hamburger era professora da área de Marketing e eu era professor da área ContábilFinanceira. O que queríamos fazer naquela época era cobrir todas as áreas de Administração e não apenas uma área específica. Como a EAESP foi fundada em 1954 e estamos falando desse grupo que começou na Escola em 1958, 59 e 60, até surgir a revista, sempre tentamos fazer a RAE atingir os leitores de todas as áreas; queríamos atingir o maior número de pessoas interessadas e olhar a Administração como um todo, mostrar ao administrador 
como ele poderia administrar e que ele poderia colocar a empresa dele numa posição atual.

RAE - Como eram selecionados e avaliados os artigos?

JCH - Os artigos eram dos professores da Escola. Nos primeiros números não havia artigos de professores externos à EAESP. Não havia avaliação, apenas revisão de português. Como eram poucas pessoas especializadas nas áreas, para encontrar pessoas que entendessem do assunto foi difícil, pois não existiam escolas de Administração de Empresas no Brasil. Como o propósito inicial era ter material para publicar, o professor Raimar procurava os especialistas de cada área.

RAE - E o público?

JCH - Como a EAESP era uma escola nova, foi criada uma relação estreita com os administradores da época. Toda comunidade empresarial estava dando apoio a nossa Escola e, provavelmente, os diretores e presidentes das empresas começaram a incentivar seus funcionários a lerem os artigos da RAE, e eles eram efetivamente lidos. Como nossa Escola teve um grande apoio das principais indústrias da época, tenho a impressão que isso ajudou na difusão da revista.

RAE - Quais foram as dificuldades encontradas no início? E como foram superadas?

JCH - A maior dificuldade era ter pessoas que escrevessem artigos, pois a área era nova no Brasil e não havia muitos professores e pesquisadores. Depois, precisávamos de pessoas que gostassem de escrever, porque era necessário pesquisar.
Acredito que fomos felizes porque éramos pioneiros, e qualquer pesquisa - não no sentido pejorativo do termo - que se escrevesse era novidade. Isso foi se desenvolvendo à medida que a escola foi tomando pulso. No começo, como a revista era quadrimestral, não era necessária uma grande quantidade de artigos. Um professor que deu muita força para a revista foi o Henrique Rattner. Ele foi um grande incentivador da revista. Depois que o Raimar deixou a revista, o Rattner continuou o trabalho. Ele foi muito importante para a continuação da revista. A Yolanda Balcão também. Ela era professora da área de Administração Geral e advogada, e tinha talento para a escrita. Foi professora da Escola durante muito tempo e teve uma participação ativa na revista. A revista sempre foi importante para a Escola, mas na época éramos poucos professores e muitos não dedicaram o tempo que deveria ser dedicado à revista.

RAE - E como o senhor vê a pesquisa em Administração de Empresas hoje?

JCH - A mudança na área de Administração foi enorme devido ao impacto da informática. Felizmente nossa Escola acompanhou esse desenvolvimento. Todas as áreas da Administração foram impactadas e modificadas pela tecnologia da informação. E, por conseqüência, os professores que escrevem aqui na revista são professores de várias áreas; a Escola acompanhou o mundo da gestão e a RAE também. A pesquisa continua evoluindo.

RAE - Pessoalmente, como foi trabalhar na RAE?

JHC - Eu participei muito, lia todos os artigos. Foi muito interessante para mim, que era professor de uma área específica, ter contato com outras áreas. Isso ampliou meu horizonte para o conhecimento de outras áreas.

\section{GISELA BLACK TASCHNER}

Diretora de janeiro de 1990 a setembro de 1991

RAE - Você assumiu a RAE em 1986, como redatora-chefe na diretoria da Maria Cecília Spina Forjaz. Poderia contextualizar esse período?

Gisela Black Taschner - Quando assumi a direção da revista, estava começando a abertura política no Brasil. No período da ditadura, a RAE acolhera vários textos que em outras revistas teria sido impossível publicar. Isso teve um aspecto positivo, mas criou também problemas, pois ela começou a se descaracterizar. De outro lado, vivíamos um processo que ainda não estava muito visível: estávamos entrando na fase da sociedade pós-industrial, pósmoderna. Fui percebendo aos poucos esses acontecimentos, porque tinha que ler todos os artigos que chegavam. Cada um vinha de uma área da Administração; aquilo foi se juntando na minha cabeça, e de repente pensei: "Meu Deus, está acontecendo uma revolução!". E realmente estava, isto é, uma revolução na produção, no comércio, a própria globalização.

RAE - E quais eram as dificuldades da época?

GBT - Primeiro, como disse, o con- 
teúdo da revista estava sem foco, excessivamente eclético; segundo, o visual dela estava mal resolvido; terceiro, apenas a Redação era em São Paulo; a editora, que era da Fundação, ficava no Rio de Janeiro e estava com problemas na época. Quando assumi a RAE, havia mais de um ano de edições que ainda não tinham saído do prelo. Portanto, a situação da revista estava complicada.

Precisávamos mudar tudo. Fizemos um projeto novo para a RAE, com a ajuda dos alunos de graduação da Escola e de alguns professores, como Sérgio Dias e Claude Machline. Uma das primeiras ações foi fazer a RAE voltar a ser uma revista de Administração. Ela continuaria a acolher contribuições externas, mas a idéia para a RAE naquele projeto era que ela fosse um porta-voz da EAESP, em todo o espectro de diversidade de idéias que sempre a caracterizou. Ela já tinha um Conselho Editorial, composto por pessoas competentes mas nem sempre com disponibilidade para participar do processo de avaliação. Então abrimos o Conselho Editorial, e todos os professores da Escola em princípio passaram a poder avaliar artigos dentro de suas áreas de expertise. Desde o início houve blind review. Aos poucos também foi criado um roteiro de avaliação. Adicionalmente, havia a questão da falta de pontualidade. Você fechava o número e ele não circulava. Chegamos à conclusão que só conseguiríamos resolver o problema assumindo a responsabilidade por todas as etapas de produção da RAE. Obtive no CNPq recursos que dariam para financiar dois números da revista. E lá fomos, eu e o Osmar Bertero, que na época era o diretor da Escola, para o Rio de Janeiro, negociar com a Fundação.
Voltamos felizes, com a autorização para trazer a revista inteira para São Paulo.

RAE - E sobre as mudanças promovidas na revista durante sua passagem, como elas foram planejadas?

GBT - Pensou-se na estrutura da Harvard Business Review, na Exame, mas prevaleceu a idéia de que a RAE tinha que ser acadêmica. Primeiro, porque não tínhamos recursos para fazer uma revista ágil e com a periodicidade de uma Exame. Depois, porque queríamos que a RAE expressasse as idéias da EAESP.

O conteúdo foi mudado em diversos aspectos. O foco já estava em Administração de novo, ainda que ela fosse tomada em seu sentido mais amplo. Foram introduzidos os editoriais, cada artigo passou a ter resumos e palavras-chave em português e inglês, criaram-se novas seções como a de colaborações de autores de outros países, informações bibliográficas e de teses, um núcleo temático em cada número, entre outras mudanças. Foi feito um novo projeto gráfico, de baixo custo, mas que ficou lindo. Em termos de organização do trabalho, eu era a redatora-chefe (sem ninguém abaixo nem acima de mim na Redação) e a diretora responsável de fato (a partir de 1990, diretora de direito também); a Ilda Fontes era $a$ funcionária da RAE. Cuidávamos juntas da Redação. Os professores da Escola avaliavam os textos. A editoração e a produção industrial passaram a ser feitas fora da EAESP, sob nossa supervisão. E a distribuição continuou a ser terceirizada.

RAE - Como você define o clima acadêmico das escolas de Adminis- tração nessa época? E quanto aos artigos publicados na $R A E$, vocês conseguiram diversificar?

GBT - Acredito que sim. Havia artigos de Gestão de Pessoas, de Economia, Contabilidade e outras áreas. Havia temas diferentes também, mas sempre relacionados com a Administração. Por exemplo, eu me lembro de um artigo do Fernando Prestes Motta, "Psicanálise nas organizações", que era absolutamente inovador. Administração, na verdade, é uma área abrangente. Aqui tínhamos muita pesquisa em algumas áreas e em outras quase nada. As pesquisas dos departamentos de Administração (ADM), de Ciências Sociais (FSJ) e de Economia (PAE) representavam quase o total das pesquisas realizadas na Escola. O desequilíbrio não era visível porque recebíamos muitas contribuições externas também. Mas a FGV tinha esse perfil heterogêneo entre os professores: um grupo mais acadêmico e outro mais de consultores. Do ponto de vista do ensino, isso era bom porque havia professores que podiam ensinar contando casos a partir da sua experiência e outros que utilizavam a abordagem mais sistemática derivada da pesquisa.

RAE - E pessoalmente, como foi trabalhar na RAE?

GBT - Como sou detalhista, tinha estresse porque me dedicava muito até ver cada número pronto. Não tinha para quem delegar as coisas, então eu e a Ilda Fontes trabalhamos muito, principalmente quando a gente trouxe a revista para São Paulo. Mas para mim foi muito interessante. Conheci professores de especialidades distintas, aprendi bastante e comecei a entender muito mais esse universo da Adminis- 
tração. Cresci muito pessoalmente, intelectualmente e profissionalmente. Tenho ótimas lembranças daquele tempo, no qual fui muito feliz, e saí da RAE com uma sensação de missão cumprida.

\section{MARILSON ALVES GONÇALVES}

Diretor de outubro de 1991 a novembro de 1995

RAE - Você poderia contextualizar sua passagem pela $R A E$ e as mudanças que promoveu nesse período?

Marilson Alves Gonçalves - Recebi a RAE como costumam ser todas as revistas acadêmicas, com uma secretária, dois microcomputadores, uma auxiliar de secretária e uma pilha de artigos para serem processados e avaliados. Percebi inicialmente as limitações. Gosto de alterar e transformar as coisas. É um traço de minha personalidade. Mas de outro lado havia uma missão. Quando fui convidado pelo então diretor, professor Michael Paul Zeitlin, para assumir a revista, tínhamos uma ambição maior, que era criar uma editora em São Paulo. Não sei se ele lembraria disso hoje. Percebi que estava diante de um negócio que chamei de Sistema RAE de Publicações. A RAE seria a ponta de um iceberg, de um sistema muito maior de comunicações da FGVEAESP. Então, fiz um plano diretor, apresentei para o diretor e ele concordou. À medida que as coisas foram se desenvolvendo, consegui encontrar uma proposta de valor para uma revista acadêmica como a $R A E$, qual seja "escrever para ser lido e não para ser publicado". Essa proposição passou desapercebida pelos professores da EAESP e, assim, continua também desapercebida pela comunidade acadêmica. Daí a minha preocupação em tornar a RAE mais palatável também para empresários, executivos e alunos.

Desde o início de minha gestão, percebi o potencial da RAE enquanto veículo de geração e difusão de conhecimento gerado pela EAESP. Decidi segmentar a publicação. Entendi que tínhamos, no mínimo, dois públicos. A partir dessa percepção, pensei numa publicação em business, que não tivesse a estrutura acadêmica, mas que também fosse uma revista fundamentada. Conversei com o diretor da Escola e fui autorizado a lançar a nova publicação. Mas levei cerca de um ano e meio para lançar essa nova revista: a RAE Light. Percebi que a sua concepção não havia sido compreendida pelo escritório técnico responsável por desenvolver o projeto gráfico. Então, com base em recortes de revistas, fiz um boneco e mandei para o sujeito que estava fazendo o projeto gráfico - materializar idéias é mais eficiente. Além disso, enfrentei o desafio, muito sério no Brasil, de não termos tradição em escrever sobre Administração para um público de profissionais da área e assemelhados.

RAE - Também pode se dizer que o passo que permitiu isso começou a ser dado quando a diretora anterior trouxe a produção da revista para São Paulo?

MAG - A iniciativa de trazer toda a produção da RAE para São Paulo foi fundamental para o que tínhamos em mente. Todavia, tínhamos herdado um cargo de redator de revista que induzia qualquer diretor da $R A E$ a desempenhar um papel de burocrata, responsável apenas por avaliar artigos e os encaminhar a uma gráfica para imprimir. Insatisfeito com isso, criei o cargo de editor da RAE e resolvi, então, fazer o que ensinamos na Escola, isto é, estabelecer parcerias e implementar uma gestão orientada por negócios e não por burocracia funcional. Era preciso estabelecer parcerias com fornecedores, senão não seria possível editar a revista no tempo certo, conseguir colaborações, sugestões para melhoria, etc. A impressão e a distribuição da revista, até então, era um vôo cego. Mandava-se uma dada edição da RAE para a gráfica, que a colocava em sua lista de prioridades, a qual não era necessariamente a nossa. Além disso, a distribuição da revista era feita em pontos que não controlávamos, até porque a grande preocupação da revista sempre foi apenas ter assinantes e não ser comercializada como um periódico convencional. Tivemos que mudar de gráfica, criar uma nova estrutura de distribuição, criar uma nova cultura de comercialização nos pontos-de-venda e, principalmente, uma nova cultura na EAESP, de lidar com um cliente que adquire a revista por vários canais de distribuição. Interiorizamos várias funções editorais essenciais na geração de diferencial competitivo, caminhando contra o senso comum de que o melhor é sempre terceirizar. Além disso, valorizamos a apresentação da revista, conseguindo o $\mathrm{Zi}$ raldo como nosso ilustrador de capa e trazendo para a revista ilustradores consagrados como o Orlando e outros. Em função de um produto melhor em apresentação e conteúdo, e da premissa de que só damos valor àquilo que pagamos bem, a ação que fiz foi elevar o preço da revista. Outra coisa foi que a revista 
teria que ser bimestral ou mensal para poder aproveitar melhor a quantidade de artigos enviados e estar mais presente na cabeça do leitor. Numa época em que as ferramentas virtuais da Internet ainda não eram de acesso ao público brasileiro em geral, ousamos lançar as bases de uma revista eletrônica, criando a RAE em separatas, a revista sendo comercializada por artigos e não apenas por todo o seu conteúdo. Finalmente, sinalizamos aos anunciantes que tínhamos uma proposta diferente.

RAE - Como você classifica o clima acadêmico e a pesquisa em administração na época?

MAG - Acredito que a história das revistas e publicações acadêmicas no Brasil seria muito diferente se não fosse a RAE. Acho que ela é um exemplo de êxito em revista que deveria ser imitado por outras revistas nas diversas áreas de pesquisa acadêmica. Sobre o clima acadêmico, acredito que havia uma espécie de amadorismo na época. Alguns escreviam porque entendiam a importância, a responsabilidade acadêmica e social de tornar pública sua pesquisa, mas tenho a impressão que na maior parte era porque dava prestígio publicar na RAE. E acho que a Capes, com essa obrigatoriedade de os pesquisadores terem que publicar, deu uma grande contribuição para o processo deixar de ser tão amador e fazer parte da atividade acadêmica. Resta saber se há conteúdo para ser lido e espaço editorial suficiente para isso.

RAE - E pessoalmente, como foi trabalhar na RAE?

MAG - Foi muito gratificante, embora eu tenha pagado - dentro da
EAESP - um preço muito alto pela ousadia que tive no campo editorial. Mas, como tudo na vida tem dois lados, por essa ousadia fui convidado a assessorar e a criar outras revistas no mercado. Aprendi muito, e acho que não seria o que sou se não tivesse passado pela experiência de ter sido editor da RAE.

\section{THOMAZ WOOD JR.}

Diretor de janeiro de 2001 a dezembro de 2004

RAE - Como você avalia sua experiência como diretor da RAE?

Thomaz Wood Jr. - Quando o Roberto Venosa, que me antecedeu como diretor, indicou-me para a diretoria da RAE, considerei um privilégio. Eu me senti totalmente à vontade para fazer mudanças. Antes de iniciar o trabalho, ouvi várias pessoas para fazer um programa de desenvolvimento para a revista. Durante o tempo em que fiquei como diretor, executei esse programa, mas também fomos criando outras coisas. Acredito que a intensidade das novidades foi muito grande, criamos muito, em parte pela diretoria da Escola, que nos deu muita liberdade, e de outro lado, a equipe interna foi muito importante. O princípio geral que norteou as mudanças na RAE foi muito simples: queríamos tornar a RAE uma revista acadêmica no padrão internacional, e uma revista acadêmica internacional tem características e processos bem definidos. Foi de grande auxílio o fato de em 1997 o Carlos Osmar Bertero, o Miguel Caldas e eu termos feito uma pes- quisa para o NPP, hoje GV-pesquisa, sobre critérios de avaliação de trabalhos acadêmicos, que permitiu que entrássemos nesse mundo e investigássemos como tudo funcionava. E deu certo. A grande dificuldade ainda é a qualidade dos artigos. A comunidade brasileira ainda não tem o padrão internacional. Ela cresceu, mas não tem ainda a capacidade de produção em um patamar internacional. Faltam-nos ainda rigor e relevância.

RAE - As mudanças foram espelhadas em quais revistas?

TW - Baseei-me em várias revistas de gestão, mas com destaque para as revistas editadas pela Academy of Management, que é a principal instituição de pesquisa em Administração dos Estados Unidos. A Academy of Management tem uma revista voltada para trabalhos empíricos e outra voltada para a teoria. A RAE faz as duas coisas. As revistas da Academy também são mais voltadas para gestão, e na RAE também temos outros campos, como Finanças e Marketing. A RAE possui um caráter mais geral.

RAE - Como você contextualiza, nesse período, a relação da $R A E$ com a pesquisa em Administração? TW - A pesquisa no Brasil está evoluindo em termos quantitativos mais pesquisadores, mais revistas, eventos cada vez maiores -, mas não tanto em termos de qualidade e impacto. Isso é uma lacuna que precisamos enfrentar. A RAE procura enfrentar esse problema sendo rigorosa na seleção de artigos e incentivando o máximo possível a conversação entre autor e avaliador no double blind review. $\mathrm{O}$ avaliador precisa ser criterioso e o autor, compreender e saber absorver as sugestões. Deve haver um diálogo real, esse é o pro- 
cesso que ajuda a desenvolver os artigos. Um artigo, quando chega à Redação, é uma boa matéria-prima, que precisa ser desenvolvida. E tal desenvolvimento é um processo longo, que requer esforço do editor, dos autores e dos avaliadores.

RAE - Houve mudanças significativas no público-alvo da RAE?

TW - Em primeiro lugar, cabe observar que a idéia de público-alvo não combina com o espírito deste tipo de revista. Na verdade, a RAE é parte de uma comunidade, uma verdadeira rede, e dentro dessa rede há os pesquisadores, os avaliadores, e essas pessoas são os produtores de conteúdo também. Quem escreve é quem lê, e quem lê é quem avalia. É uma comunidade única, onde a cada momento você pode estar em um papel diferente. Penso que esse é o melhor conceito. Analisando essa comunidade, acredito que estamos num estágio de conhecimento ainda rudimentar no Brasil. Há também o desafio enfrentado por toda a comunidade acadêmica no mundo, que é o de romper o isolamento com relação à prática. Administração é uma ciência aplicada, você não pode se isolar. E aqui, como em outros lugares, o pesquisador se isola, vivendo em um universo à parte. Essa é uma mudança significativa que ainda está por ser feita.

RAE - Como foi criada a RAE-eletrônica?

TW - O principal motivo para a criação da RAE-eletrônica foi a consideração de que o meio eletrônico constitui uma tendência forte em termos de divulgação da produção acadêmica. Usar meios eletrônicos, em especial a Internet, traz muitas vantagens. Reduz o ciclo de processamento dos artigos, reduz custos, facilita o acesso e reduz o ciclo entre a submissão e a veiculação. Além disso, o meio tem grande flexibilidade em termos de formato, permitindo interatividade e formas mais abertas de comunicação. O processo de criação da RAE-eletrônica foi relativamente simples. Emulamos os processos e diretrizes da RAE e acrescentamos uma política editorial específica. Naturalmente, houve um desenvolvimento paralelo do suporte tecnológico, essencial para viabilizar o projeto. Em termos de relevância para o meio acadêmico, creio que a principal contribuição da revista é constituir um espaço totalmente aberto, com consulta gratuita. De fato, o número de acessos é significativo e crescente.
RAE - E a GV-executivo, como foi criada?

TW - A GV-executivo foi criada para atender uma parte considerável do público da própria FGV-EAESP, que tem um perfil executivo e que recebia a RAE. Precisávamos de uma revista com linguagem mais adequada e com informações para esse público, que é formado por profissionais que buscam aperfeiçoamento nos programas executivos da Escola. Pelas informações que recebemos, acredito que a revista se tornou uma fonte complementar de leituras, comumente indicadas aos alunos pelos próprios professores. Penso que é importante ter uma alternativa de leitura como a GV-executivo, porque ela busca ter posições mais arejadas e críticas sobre as questões de gestão e organização, e se diferencia dessa forma das outras revistas existentes.

RAE - Pessoalmente, como foi trabalhar na RAE?

TW - Foi muito intenso. Ser editor significa manter a mente permanentemente alerta no processo de geração de conteúdo da revista. Foi também um trabalho gratificante, pelo apoio do pessoal de Redação, que é excepcional e sabe manter o espírito sempre elevado, mesmo em condições de trabalho difíceis. 